\title{
Trabajadores, empresas y comunidades urbanas: reflexiones introductorias
}

\author{
Silvia Simonassi \\ Investigaciones Socio-históricas Regionales \\ CESOR/Universidad Nacional de Rosario \\ silviags@express.com.ar \\ Laura Badaloni \\ Investigaciones Socio-históricas Regionales \\ ISHIR - CONICET \\ labadaloni@gmail.com
}

En este dossier nos proponemos presentar algunos debates en torno a las maneras de hacer Historia del Trabajo, articulando las políticas patronales de disciplinamiento y las estrategias obreras, en relación con la construcción de una determinada territorialidad. ${ }^{1}$

Algunos de los conceptos que han sido propuestos para pensar dicha articulación fueron: paternalismo industrial, disciplina industrial, capitalismo benefactor (welfare capitalism), bienestar industrial (industrial welfare), para sólo citar los más frecuentes.

Una revisión de estas formas de aproximación nos remite al momento en que la obra de Harry Braverman Trabajo y Capital Monopolista ${ }^{2}$ viera la luz en el mundo anglosajón. Su

1 Las reflexiones que siguen profundizan y completan las contenidas en SIMONASSI, Silvia, "Pensando las relaciones obrero-patronales: reflexiones teóricas y aproximaciones históricas a las plantas metalúrgicas de Rosario (1940-1980)”, ponencia presentada en las Jornadas Refinería, Rosario, 2001; "Conflictividad laboral y políticas disciplinarias en la industria metalúrgica de la ciudad de Rosario 1973-1976" en Anuario IEHS, Tandil, 2007, № 22, pp. 465-486 y BADALONI, Laura, "Prácticas empresarias paternalistas: sus alcances y límites en el disciplinamiento y control de la mano de obra. El caso del Ferrocarril Central Argentino durante las primeras décadas del siglo XX en Rosario y alrededores", en Ídem. pp. 507-524.

2 BRAVERMAN, Harry, Trabajo y Capital Monopolista. La degradación del trabajo en el siglo XX, Ed. Nuestro Tiempo, México, 1984. La primera edición en inglés es de 1974. Un año después, en 1975 fue traducida y publicada en español. El núcleo central de la obra de Braverman consiste en la afirmación que la historia del capitalismo puede formularse como la búsqueda incesante del control

SIMONASSI, Silvia, BADALONI, Laura, "Trabajadores, empresas y comunidades urbanas: reflexiones introductorias”, en Avances del Cesor, Año X, № 10, 2013, pp. 101-111. 
reflexión acerca de la relevancia del estudio de los procesos de trabajo y sobre la búsqueda incesante por parte de los capitalistas para lograr su control, dejó una impronta en los análisis posteriores de sociólogos, economistas e historiadores. Esta "reconstrucción creadora" de la teoría de Marx, ${ }^{3}$ ha conducido a potenciar los estudios que centran la mirada en el lugar de trabajo, en el sitio de desenvolvimiento de la relación capital-trabajo, allí donde la interacción de clases se hace más transparente, el sitio de conflicto por excelencia.

No obstante la profunda marca que en los estudios de esta índole produjera el análisis de Braverman, sucesivos trabajos insistieron en aspectos ignorados de esta obra fundante. Tal vez uno de los más sugestivos sea el provocativo texto de Michael Burawoy El consentimiento en la producción, en el cual se afirmaba que "el consentimiento espontáneo se une a la coacción para generar actividades productivas". De este modo, admitiendo el interés de la dirección por controlar el proceso productivo, se introduce la racionalidad obrera ya no presentada en los tradicionales términos de conflicto, sino, por el contrario, a partir del análisis del consentimiento. ${ }^{4}$

Inscripto en otra tradición teórica y fuera del mundo anglosajón, Jean -Paul De Gaudemar ${ }^{5}$ coincide en el señalamiento de los aspectos políticos de las relaciones sociales de producción. El autor ubica a la necesidad del capital ${ }^{6}$ por imponer su disciplina en un lugar

sobre el proceso de trabajo por parte de los capitalistas. En este recorrido, una de las líneas centrales de su pensamiento, reside en la constatación de la tendencia del Capital a la descualificación de la fuerza del trabajo mediante la destrucción de los oficios y la progresiva monopolización del conocimiento científico por parte de la administración patronal, lo cual se ha presentado históricamente como la separación entre la concepción y la ejecución. En su trabajo, quedan al descubierto las relaciones de poder que sustentan la producción capitalista en su fase monopolista.

3 BURAWOY, Michael, El consentimiento en la producción. Los cambios del proceso productivo en el capitalismo monopolista, Ministerio de Trabajo y Seguridad Social, Madrid, 1989, p.13.

4 Una de las aportaciones de su trabajo consiste en pensar el proceso productivo como un juego que genera consentimiento, desplazando en ocasiones el conflicto entre trabajadores y dirección hacia otro, donde se enfrentan grupos de trabajadores entre sí. La perspectiva de Burawoy contribuye en la comprensión de las formas en que los mecanismos de control impuestos por la dirección pueden ser reformulados, suavizados o transformados completamente por el accionar de los trabajadores y que en su trazado operan las particulares culturas del trabajo sobre las que se imprime la acción patronal.

5 DE GAUDEMAR, Jean-Paul: El orden y la producción. Nacimiento y formas de la disciplina de fábrica, Editorial Trotta, Madrid, 1991.

6 En rigor, ya Carlos Marx señaló la necesidad del Capital por imponer su disciplina en el proceso de trabajo dentro de la fábrica: "La supeditación técnica del obrero a la marcha uniforme del instrumento de trabajo y la composición característica del organismo de trabajo, formado por individuos de ambos sexos y diversas edades, crean una disciplina cuartelaria... El código fabril en que el Capital formula, privadamente y por su propio fuero, el poder autocrático sobre sus obreros, sin tener en cuenta ese régimen de división de los poderes de que tanto gusta la burguesía, ni el sistema representativo de que gusta todavía más, es simplemente la caricatura capitalista de la reglamentación social del proceso 
analítico central. ${ }^{7}$ Allí donde el análisis de Braverman y Burawoy se centra en los trabajadores, De Gaudemar restringe su análisis a las estrategias patronales y en este registro, se interesa por las representaciones que sobre las técnicas disciplinarias construyen los capitalistas, sin considerar las prácticas. Un análisis conjunto podría descubrir fisuras en los ciclos disciplinarios pensados como modelos ${ }^{8}$ y permitiría poner en tensión lo que el propio De Gaudemar señala como necesario, es decir, comprobar el modo como las luchas, la resistencia obrera y las "actitudes de indisciplina" inciden sobre las técnicas disciplinarias. Entre estas últimas, el autor señala la que él denomina modelo de disciplina paternalista, concepto apropiado para analizar fenómenos como la fábrica-ciudad o company-town. En ellos la voluntad patronal se orienta -tomando como base la estructura familiar- a organizar "alrededor de la fábrica un espacio social en los que los muros de la fortaleza se derrumbarían para dejar paso a barreras más simbólicas pero igualmente infranqueables". ${ }^{10}$ Se trata para De Gaudemar, de la intención de disciplinar la fábrica disciplinando también lo que está fuera de ella.

Este propósito patronal de incidir en los tiempos extra-laborales fue abordado por diversos autores a través del concepto de paternalismo industrial. Así, José Sierra Álvarez ha investigado en España, para las explotaciones mineras de Asturias de fines del siglo XIX y

de trabajo" en MARX, Carlos, El Capital, T. 1, Fondo de Cultura Económica, México, 1973, pp. 350-351.

7 Apartándose de aquellos análisis que diferencian una "mala" disciplina -opresión pura, o sea, necesidad de los patrones de afirmar su poder en el lugar de trabajo- de otra "buena" -aquella que surge de la necesidad de los capitalistas de poner en funcionamiento, sobre bases técnicas, un colectivo destinado a la producción-, destaca la profunda unidad entre ambas: en última instancia, la primera constituye su condición de posibilidad. La reflexión de De Gaudemar abreva fundamentalmente en FOUCAULT, Michel, Vigilar y castigar. Nacimiento de la prisión, Siglo Veintiuno Argentina, Buenos Aires, 2005, pp. 141-142.

8 De Gaudemar señala cuatro formas disciplinarias: la fábrica-fortaleza, la fábrica-ciudad, la fábrica-máquina y la fábrica democrática, en DE GAUDEMAR, Jean Paul: El orden..., Op. Cit., pp. 66-105.

9 Son ejemplos de actitudes de indisciplina para De Gaudemar: el ausentismo, las borracheras, la pereza en el trabajo, etc. La interpretación unívoca de estos comportamientos como formas de resistencia ha sido materia de discusión. Ver: EDWARDS P. K. y SCULLION Hugh, La organización social del conflicto laboral. Control y resistencia en la fábrica, Centro de Publicaciones Ministerio de Trabajo y Seguridad Social, Madrid, 1987; MONTES CATÓ, Juan, "Reflexiones teóricas en torno al estudio del conflicto laboral. Los procesos de construcción social de la resistencia" en Trabajo y Sociedad. Indagaciones sobre el trabajo, la cultura y las prácticas políticas en sociedades segmentadas, $\mathrm{N}^{\circ} 9$, V. IX, Invierno 2007, Santiago del Estero, Argentina; DICÓSIMO, Daniel, "La indisciplina colectiva e individual en la industria metalúrgica. Desafíos al orden social durante el Proceso de Reorganización Nacional, 1976/190", en Anuario IEHS, Tandil, 2007, № 22, pp.445-463.

10 DE GAUDEMAR, Jean Paul: El orden..., Op. Cit., p. 76. 
principios del siguiente, el despliegue de prácticas patronales que conforman "un programa de conjunto de formación y gestión de la mano de obra". Para el autor, el paternalismo industrial articula "estrategias patronales de disciplinamiento productivo" y "estrategias burguesas de disciplinamiento reproductivo y social". Dentro de estas últimas se enmarcarían los intentos de avanzar sobre la vida de los trabajadores fuera de los espacios de labor con la intención de producir "un obrero modelo: más fuerte (en el trabajo, en sus relaciones con la materia) y más débil (en el mercado de trabajo, en sus relaciones con el patrón)"." Si bien el despliegue de estos dispositivos ha sido asociado a la ausencia del estado liberal en estas dimensiones del mundo del trabajo, el concepto ha sido reapropiado para etapas posteriores del desarrollo estatal y las relaciones laborales.

Es el caso de José Babiano Mora, ${ }^{12}$ para quien durante la España franquista se habrían aplicado modalidades de gestión y control de mano de obra que configuraban un "conjunto coherente de dispositivos desplegados en la esfera de la reproducción", basados en las "obras sociales" (vivienda obrera, comedores de empresa, economatos, escuelas infantiles, actividades culturales, deportivas y festivas, préstamos monetarios y cajas de asistencia) y cuyos objetivos eran la atracción y estabilidad de la mano de obra, su disciplinamiento productivo y la generación de lazos de lealtad vertical. ${ }^{13}$ Desde esta perspectiva, el paternalismo industrial aparece como funcional al momento de incorporación del modelo fordista, asumido por empresas industriales o de servicios, en general con posibilidades de invertir en dispositivos de este tipo. Para el autor, las prácticas paternalistas tenían un carácter de concesión para determinados fines y podían ser retiradas arbitrariamente. En este sentido, el paternalismo industrial, concebido como complemento o sustitución de un estado ausente o débil, abre paso a la posibilidad de su coexistencia con regímenes de mayor intervención estatal y con las políticas sociales desplegadas por las organizaciones sindicales en pleno siglo XX. ${ }^{14}$

11 SIERRA ÁLVAREZ, José: El obrero soñado. Ensayo sobre el paternalismo industrial (Asturias 1860-1917), Siglo veintiuno Editores, Madrid, 1990, pp. 3, 77 y 83.

12 BABIANO MORA, José, Paternalismo Industrial y desarrollo fabril en España (1938-1959), Consejo Económico Social, Madrid, 1998, p. 160 y ss.

13 Ídem. p. 156.

14 En la tradición española de historia empresaria y de historia del trabajo encontramos una producción abundante, que procura abordar el problema de las relaciones obrero patronales a través de esta conceptualización. Para sólo citar algunos aportes de la profusa producción que apela al concepto, consultar: IBARZ, Jordi, "Paternalismo industrial en el puerto de Barcelona. 1939-1947", en Comunicaciones presentadas al II Encuentro de Investigadores del Franquismo, T.2, Alicante, 13-15 de mayo, 1995; PEÑA RAMBLA, Fernando, “La industria segarra de la Vall D’Uixo: un ejemplo de paternalismo franquista", en Comunicaciones presentadas al II Encuentro de Investigadores del Franquismo, T.1, Alicante, 13-15 de mayo, 1995 y del mismo autor: "Paternalismo y control social en la industria franquista. La empresa Segarra de la Vall D’Uixó”, en Sociología del Trabajo, nueva época, otoño de 
En otras realidades, como el Reino Unido, ${ }^{15}$ se constatan trabajos que hacen hincapié en tradiciones paternalistas originadas en el siglo XIX, las cuales brindaron modelos para desarrollos posteriores, durante la centuria siguiente, materializados en programas de bienestar empresario: "Luego de la primera Guerra Mundial el company welfarism se expandió significativamente en la industria británica, especialmente en las industrias más nuevas. La provisión de pensiones creció notablemente en los años '20. Las compañías de ferrocarriles y la industria del gas continuaron con una orientación explícitamente de bienestar y su posición monopólica facilitaba el financiamiento de sofisticados programas de bienestar". ${ }^{16}$ Robert Fitzgerald, ${ }^{17}$ adopta el concepto Industrial Welfare y señala que las empresas ferrocarrileras británicas ${ }^{18}$ veían como importantes elementos tales como "incentivos, motivación y lealtad..." a la hora de evitar huelgas o retener mano de obra calificada. Estas preocupaciones las llevaron a establecer seguros de empleos, fondos de pensión, amplios mercados internos de trabajo, programas de viviendas, asociaciones mutuales para empleados, etc. Fitzgerald considera relevante explorar las políticas empresarias encaminadas a la integración de la fuerza de trabajo, aspecto pasado por alto, por ejemplo, en el análisis de Alfred Chandler ${ }^{19}$ sobre el advenimiento de la empresa gerencial.

El uso del concepto ha despertado dudas sobre el verdadero lugar ocupado por la conflictividad en el análisis de las relaciones laborales. En otros términos, hablar de paternalismo industrial ¿supone considerar a los trabajadores como sujetos débiles, controlados,

1998, N³4; ARENAS POSADAS, Carlos, Empresa, mercados, mina y mineros. Rio Tinto, 1873-1936, Universidad de Huelva/Fundación Rio Tinto, España, 1999; CUEVAS RUIZ, Fernando, "Ferrocarril, carbón y Paternalismo industrial en Barruelo de Santullán, IV Congreso Historia Ferroviaria, Málaga, 2006; DE LOS COBOS ARTEGA, Francisco y MARTÍNEZ VARA, Tomás, "Gestión del conflicto laboral en las grandes empresas. Los modelos de la dirección de las compañías ferroviarias Norte y MZA", V Congreso Historia Ferroviaria, Palma, 2009.

15 Para un análisis del vínculo entre las políticas empresarias de bienestar-welfare Capitalism/ workplace welfare-y los orígenes del Estado de Bienestar británico, ver: MELLING, Joseph, "Welfare Capitalism and the origins of welfare states: British Industry, workplace welfare and social reform, c. 1870-1914” en Social History, V. 17, № 3, 1992.

16 MCIVOR, Arthur y WRIGHT, Cristopher, "Managing Labour 1900-50" en Labor History, mayo de 2005, No 88 , pp. 51 y 52, (Traducción de las autoras).

17 FITZGERALD, Robert, "Employment Relations and Industrial Welfare in Britain: Business Ethics versus Labor Markets" en Business and Economic History, Fall 1999, V. 28, N 2.

18 También para empresas ferroviarias en el Reino Unido ver: HOWLETT, Peter, "The internal dynamics of the Great Eastern Railway Company, 1870-1913." en Economic History Review, 2004, LVII, No 2, pp. 396-422; HANNAH, Leslie, "Why Employer-Based Pension Plans? The Case of Britain”, The Journal of Economic History, junio 1985, Vol. 45, No. 2.

19 CHANDLER, Alfred, Escala y diversificación. Las dinámicas del capitalismo industrial, Prensas Universitarias de Zaragoza, Zaragoza, 1996. 
amenazados, y expropiados de toda racionalidad? Un excesivo énfasis en el paternalismo en tanto práctica empresaria, puede tender a difundir esa idea. Sin embargo, un uso preciso de este concepto requeriría no pensar a los trabajadores como meros sujetos pasivos, receptores de políticas frente a las cuales su comportamiento no cuenta, sino por el contrario, es imperioso considerar el accionar obrero, que puede estimular, modificar o interrumpir el despliegue de dichas prácticas.

Diversos autores señalaron el modo en que la coacción representó una condición para reclutar obreros industriales en los orígenes del capitalismo de entre una masa de campesinos y artesanos no dispuestos a disciplinarse fácilmente. ${ }^{20}$ Pero ha sido sin duda un historiador, Edward Thompson, quien, en un trabajo fundante, demostrara agudamente el carácter conflictivo de la introducción del tiempo y la disciplina capitalistas entre sociedades orientadas al "quehacer". ${ }^{21}$ Una vez que las generaciones posteriores internalizaron el ritmo fabril, el poder patronal en planta ha necesitado hallar formas de legitimación diversas según los contextos y, como afirma De Gaudemar, "queriendo cambiar de imagen, los patronos cambian también de disciplina". ${ }^{22}$ No obstante, es necesario también insistir en la idea de que los trabajadores no promueven todo el tiempo el conflicto ni necesariamente los patronos imponen siempre pura coacción. Justamente porque el lugar de trabajo es un lugar conflictivo por definición -y no por lo contrario- los estudios sobre los esfuerzos patronales para garantizar el consenso en planta, no niegan el conflicto sino que resaltan la necesidad del despliegue de políticas -concientes, explícitas-destinadas a la creación de un clima de paz social adecuado a los intereses del capital.

Otras interpretaciones -como es el caso de los estudios de company towns-han realizado aportes significativos, articulando el análisis de las políticas de fijación y gestión de la mano de obra con las experiencias de resistencia y luchas obreras en comunidades urbanas y obreras particulares. ${ }^{23}$

En el caso específico de Argentina, si bien la dimensión comunitaria de la protesta social y política ha sido recurrentemente transitada, son escasos -aunque particularmente estimulantes- los trabajos que convierten a la relación entre fábrica y comunidad en objeto

20 BRAVERMAN, Harry, Trabajo y Capital..., Op. Cit.; De Gaudemar, El orden y la producción..., Op. Cit.; MARGLIN, Stephen, "Orígenes y funciones de la parcelación de tareas ¿Para qué sirven los patronos?", en GORZ, André (compilador), Crítica de la división del trabajo, Laia, Barcelona, 1977.

21 THOMPSON, Edward, "Tiempo, disciplina de trabajo y capitalismo industrial”, en Tradición, revuelta y conciencia de clase, Crítica, Barcelona, 1984.

22 DE GAUDEMAR, Jean-Paul, El orden y la producción..., Op. Cit.

23 Consultar al respecto: Oliver Dinius and Angela Vergara (editores) Company Towns in the Americas: landscape, power, and Working-Class Communities, The University of Georgia Press, Athens, 2011 y los artículos de Vergara, Dinius y Soul que integran este dossier. 
de estudio. ${ }^{24}$ Federico Neiburg en su análisis sobre Loma Negra, a partir del concepto de "sistema de fábrica con villa obrera" fue quien más claramente procuró reflexionar en torno a un caso "clásico". El concepto remitiría al caso típico de la actividad de extracción minera, donde ante el aislamiento e inexistencia de un mercado de trabajo constituido previamente, las políticas patronales tendieron a atraer a la mano de obra generando y estructurando un mercado de trabajo para fijar e inmovilizar a los trabajadores - particularmente mediante la provisión de vivienda- disciplinándolos para la vida productiva y para la aceptación de la autoridad patronal. Esta tarea requirió del control de la vida en el trabajo pero también y fundamentalmente de la vida fuera del trabajo, del disciplinamiento y la moralización en la esfera de la reproducción. ${ }^{25}$

Asociadas al particular dinamismo de la historia regional en centros universitarios del interior, encontramos investigaciones destinadas a reflexionar acerca de las comunidades conformadas alrededor de los campamentos petroleros a lo largo del siglo XX. Esta producción responde a la centralidad de estas actividades productivas en una amplia región del sur argentino y al particular modo a partir del cual se configuraron espacios urbanos articulados al mundo del trabajo del petróleo y el carbón. En un registro similar, los estudios sobre los entornos productivos, territoriales y las tramas sociales de la producción siderúrgica en Jujuy (Altos Hornos Zapla), representan prolíficas líneas de investigación. ${ }^{26}$

24 Desde el campo de la historia social del trabajo, sin duda el aporte más significativo es LOBATO, Mirta, La vida en las fábricas. Trabajo, protesta y política en una comunidad obrera, Berisso (1904-1970), Prometeo Libros-Entrepasados, Buenos Aires, 2001. Desde la historia empresaria y de la inmigración: BARBERO, María Inés y CEVA, Mariela, "La vida obrera en una empresa paternalista”, en DEVOTO, Fernando y MADERO, Marta (directores) Historia de la vida privada en la Argentina, T. 3. La Argentina entre multitudes y soledades. De los años 30 a la actualidad, Taurus, Buenos Aires, 2000; RUSSO, Cintia, "Fábrica y localidad: la construcción de la identidad industrial: el caso de la Cervecería y Maltería Quilmes", H-industria, primer semestre de 2008, № 2, año II; "Identidad urbana, territorio y empresa. Un caso de la zona sur de la región metropolitana de Buenos Aires”, en Scripta Nova. Revista electrónica de Geografía y Ciencias Sociales, 1 de agosto de 2010, V. XIV, No 331 (90); CEVA, Mariela, Empresas, trabajo e inmigración en la Argentina. Los casos de la Fábrica Argentina de Alpargatas y la Algodonera Flandria (1887-1955), Biblos, Buenos Aires, 2010. Desde la Antropología, y para el caso de SOMISA, en la provincia de Buenos Aires, consultar el trabajo de Maria Julia Soul incluído en este dossier. Además: PALERMO, Hernán M., Cadenas de oro negro en el esplendor y ocaso de YPF, Antropofagia, Buenos Aires, 2012.

25 NEIBURG, Federico, Fábrica y villa obrera: historia social y antropología de los obreros del cemento, CEAL, Buenos Aires, 1988, V. 1 y 2. El concepto remite a LEITE LOPES, José Sergio, "Fábrica e vila operaria: consideracoes sobre uma forma de servidao burguesa", en Mudanca social no nordeste. A reproducao da subordinacao, Ed. Paz e Terra, Río de Janeiro, 1979.

26 CABRAL MARQUES, Daniel: "Conflicto e intervención estatal en los orígenes de la actividad petrolera. Comodoro Rivadavia (1915-1930)" en CABRAL MARQUES, Daniel y PALMA GODOY, Mario, Distinguir y comprender. Aportes para pensar la sociedad y la cultura en Patagonia, Ediciones 
Por su parte, las investigaciones sobre las empresas ferroviarias han evidenciado la existencia de sistemas de servicios sociales construidos a partir de beneficios adicionales extra-salariales (viviendas, servicios de salud, actividades de recreación y préstamos monetarios) que buscaban tanto atraer y retener mano de obra como involucrar a sectores de trabajadores con los intereses empresarios. ${ }^{27}$ Otros trabajos han subrayado las dificultades de los pequeños y medianos industriales de la provincia de Santa Fe para montar complejas estructuras de bienestar, en tanto reforzaban determinadas prácticas que se acercaban al paternalismo industrial, sin reproducir un modelo acabado y completo, configurando prácticas de tipo paternalista..$^{28}$

Si bien estos aportes presentan importantes diferencias en los modos de abordaje de las relaciones entre empresarios, trabajadores y comunidades urbanas, consideramos que el análisis de estas tramas, brinda la posibilidad de articular en el análisis, políticas de gestión de la mano de obra dentro del lugar de trabajo y fuera de sus muros -en el tiempo libre de los trabajadores y sus familias- con el accionar de los trabajadores, sus reapropiaciones y las posibles respuestas. Por otro lado, permite interrogarnos acerca de los procesos de territorialización de la fuerza de trabajo en comunidades fabriles "totales" o "parciales", es decir, acerca de la existencia de comunidades enteramente permeadas por las relaciones emergentes de las fábricas así como de microespacios inmersos en comunidades urbanas de mayores dimensiones. Esto conduce también a la reflexión acerca de las relaciones con el entorno, los vínculos más o menos intensos entre la comunidad fábrica y la ciudad, provincia, región o estado nacional (y sus actores); en otros términos, la mayor o menor condición de "aislamiento" a los cuales se encuentran sometidos los colectivos obreros.

Proyección Patagónica, Comodoro Rivadavia, 1995; CABRAL MARQUES, Daniel y CRESPO, Edda Lía, "Entre el petróleo y el carbón: empresas estatatales, trabajadores e identidades sociolaborales en la Patagonia Austral, 1907-1976, en BANDIERI, Susana, BLANCO, Graciela y VARELA, Gladys (directoras) Hecho en Patagonia. La historia en perspectiva regional, CEHIR-Facultad de Humanidades Universidad Nacional del Comahue, Neuquén, 2006; BOTO, Maria Salomé, "La fuerza laboral de Altos Hornos Zapla: 1943-1949”, ponencia presentada a las XI Jornadas Interescuelas Departamentos de Historia, Tucumán, 2007; BERGESIO, Liliana y GOLOVANEVSKY, Laura (editoras) Industria y sociedad. El sector manufacturero em Jujuy y Argentina, EDIUNJu, San Salvador de Jujuy, 2012.

27 PALERMO, Silvana, "Protesta laboral, nacionalismo e internacionalismo: La huelga ferroviaria de 1917 en tiempos de la Gran Guerra”, XXI Jornadas de Historia Económica, Universidad Nacional de Tres de Febrero, 2008. BADALONI, Laura, "La familia ferroviaria a principios del siglo XX: bienestar y lealtades de hierro en el Ferrocarril Central Argentino" en DICÓSIMO, Daniel y SIMONASSI, Silvia (compiladores) Trabajadores y empresarios en la Argentina del siglo XX. Indagaciones desde la Historia Social, Prohistoria Ediciones, Rosario, 2011, pp 143-157.

28 SIMONASSI, Silvia, Historias de Metal. Industria e industriales metalúrgicos de Rosario, 1973-1983, tesis de maestría, Rosario, 2004 y "Labor and Community in post war Argentina: the Agro-Machinery Industry in Firmat, Santa Fe", DINIUS, Oliver and VERGARA, Angela (editores) Company Towns..., Op. Cit. 
En los análisis existentes hasta el momento, las condiciones estructurales se entrelazan con la agencia humana, advirtiendo acerca de la necesidad de integrar el análisis de las ramas de producción, los procesos de trabajo, la tecnología, las relaciones sociales, la construcción social de los espacios, las historias empresarias y las trayectorias de los colectivos de trabajadores. No en todos los casos encontramos el conjunto de elementos actuando en interacción. A menudo la conformación del mercado de trabajo no nació como resultado del esfuerzo deliberado de los empresarios, ni la política de fijación de la mano de obra consistió en la dotación de vivienda gratuita a los trabajadores, aunque sí aparezcan políticas destinadas a facilitar su acceso. No siempre los empresarios optaron por controlar en todos los planos la esfera de la reproducción de la fuerza de trabajo, aunque desplegaran políticas selectivas a tal fin. Y por último, las respuestas de los trabajadores dependieron de un conjunto complejo de circunstancias generando experiencias confrontacionistas o consensuadas que requieren ser analizadas históricamente.

Con el propósito de intervenir en estos debates, presentamos el presente dossier. El mismo contiene cuatro trabajos presentados en el "II Workshop Historia de las relaciones laborales en la Argentina del Siglo XX", realizado en la sede del ISHIR-CESOR/CONICET de Rosario, los días 23 y 24 de agosto de 2012. Los trabajos de Ángela Vergara, María Julia Soul, Daniel Cabral Marques y Griselda Lemiez fueron discutidos entre los participantes e integran los comentarios y sugerencias vertidas en esas jornadas de trabajo. José Carlos Matos Pereira y Oliver J. Dinius accedieron gentilmente a enviar sus contribuciones, brindándonos la posibilidad de concretar esta selección de trabajos, donde pretendemos hacer ostensibles algunas de las diversas maneras de pensar y escribir la historia del trabajo y dejar abiertos interrogantes para futuros debates.

Ángela Vergara reflexiona en torno al paternalismo industrial, las ciudades empresa y los campamentos mineros desde una perspectiva transnacional o translocal, incursionando en uno de los más importantes debates actualmente en curso en el campo de la historia del trabajo. Es justamente desde esa perspectiva -encaminada a superar las historias locales y regionales del trabajo y por este camino, a establecer comparaciones- que la autora analiza las prácticas empresariales empleadas en América Latina para afrontar los procesos de modernización e industrialización. Enfocando particularmente la industria minera latinoamericana y chilena, reflexiona acerca de los límites de aplicación del paternalismo industrial. José Carlos Matos Pereira analiza el proceso de instalación de la Companhia Ford Industrial do Brasil, en la Amazonia brasileña, para la extracción de caucho y la construcción de una ciudad-empresa inspirada en las experiencias norteamericanas. Para el autor, este proceso consistió en el disciplinamiento y control de una mano de obra mayoritariamente migrante y aunque asalariada, escasamente influida por la versión norteamericana del fordismo. Articulando diversas escalas, locales, federales y transnacionales, Matos Pereira reflexiona acerca del proceso de urbanización y modernización de un espacio periférico latinoamericano, en un período posterior al boom del caucho. Estos artículos nos invitan a reflexionar en torno al carácter "importado" de este modo de gestión de la fuerza de trabajo en las compañías 
de capitales europeos o norteamericanos instaladas en toda América Latina sobre fines del siglo XIX y principios del XX. Asimismo, nos conducen a pensar en torno a su posibilidad de reproducción en otras empresas de origen local, tanto privadas como estatales, como proponen los artículos que se presentan a continuación.

Así, Oliver Dinius define la construcción de la planta siderúrgica de Volta Redonda y de un company town asociado a la misma, en Brasil durante el gobierno del Estado Novo, como un proyecto de paternalismo estatal. El mismo inclúa programas de asistencia social y bienestar para sus empleados pero al mismo tiempo un férreo sistema de control y castigo. Ambos elementos, señala el autor, fueron concebidos como las dos caras de una misma moneda. La idea utópica de construir una suerte de "familia siderúrgica" enraizada en la ideología católica, encontró límites en su desarrollo que fueron usados como punto de partida por los trabajadores para fundamentar sus propias reivindicaciones. El trabajo de Julia Soul también se focaliza en una empresa siderúrgica estatal -SOMISA en Argentinay su vínculo con la comunidad de emplazamiento de trabajadores. La autora se interesa por la forma en que un conjunto de prácticas e intervenciones referidas a los procesos de producción y reproducción de la fuerza de trabajo posibilitaron el proceso de formación de los obreros industriales - especialmente los de SOMISA- como parte de la clase trabajadora. Al mismo, tiempo, las políticas de reclutamiento y estratificación de la fuerza de trabajo contribuyeron a la configuración del colectivo somisero como conjunto diferenciado frente al resto de los trabajadores de la ciudad. Su segmentación interna derivó - según la autora - en que la forma de company town quedara limitada a los estratos superiores de la compañía vinculados, además, a un mercado de trabajo especializado.

El trabajo de Daniel Cabral Marques se centra en las formas de organización sindical que estuvieron presentes en el área de la Cuenca petrolera del Golfo San Jorge en Argentina, durante la primera mitad del siglo XX. En esta zona predominaban industrias extractivas entre ellas la empresa estatal de petróleo, Yacimientos Petrolíferos Fiscales (YPF). El período explorado incluyó momentos signados por violentos choques entre trabajadores, empresa y Estado. El artículo reconstruye el origen convulsivo - de algún modo olvidado y reprimido por la comunidad obrera - del posterior régimen de consenso establecido en los años ' 50 a partir de la constitución de company towns vinculados a YPF y a otras producciones extractivas. En ese sentido, las empresas desarrollaron un conjunto de acciones sistemáticas buscando incidir no sólo en el ámbito productivo sino avanzar en el campo de la reproducción (provisión de viviendas, sistemas de salud, servicios urbanos, proveedurías, regulación del tiempo libre, etc.). Griselda Lemiez se propone en su trabajo analizar las relaciones laborales construidas en torno al proceso de producción de la industria cementera de la ciudad de Olavarría en Argentina. El espacio donde se desarrollan estos vínculos configura un sistema de fábrica con villa obrera, un entramado particular de relaciones sociales dominado por una gran empresa. En su interior las condiciones de trabajo aparecen limitando y determinando en gran medida las formas de vida y las relaciones extralaborales. Las fuentes privilegiadas en la investigación primaria en que se basa este artículo fueron expedientes judiciales que 
detallan las causas y formas de los conflictos suscitados en tres cementeras de la zona. La autora afirma que las relaciones laborales al interior de los lugares de trabajo fueron moldeadas tanto por las estrategias empresariales como por los comportamientos obreros que intenta rescatar a partir de los conflictos analizados.

De modo que los artículos reunidos en este dossier sugieren diferentes líneas de análisis que invitan a la comparación de las formas diversas en que se materializó este particular modo de gestión de la fuerza de trabajo y a la ponderación de los alcances y límites del mismo. ¿Es posible diferenciar entre un paternalismo represivo y otro consensual? ¿O se trata de dos facetas inextricablemente unidas, que se solapan mutuamente? ¿Hasta que punto el paternalismo industrial es exitoso en cuanto a evitar el conflicto en los lugares de trabajo o en los espacios que configura bajo su influencia? Otros interrogantes surgirán de los análisis que siguen, que esperamos inspiren futuras investigaciones que recuperen una mirada relacional y territorial de las relaciones de clase. 